Tenuй Oрпопедии № 3, 2015 г.

Лучшие научные постерные доклады молодых ученых, представленные на научно-практической конференции с международным участием «ИЛИЗАРОВСКИЕ ЧТЕНИЯ», 10-11 июня 2015 г., г. Курган

(C) Е.А. Захарьян, 2015.

УДК 616.718.5/.6-001.59-053.1-053.2

DOI $10.18019 / 1028-4427-2015-3-84-86$

Ранние результаты коррекции деформаций нижней конечности репозиционным
узлом «ОРТО-СУВ» у детей с врожденным ложным суставом костей голени

Е.А. Захарьян

СЗГМУ им. И.И. Мечникова, г. Санкт-Петербург

\title{
Early results of correction of the lower limb deformities in children with congenital pseudoarthrosis of leg bones using "ORTO-SUV" reposition unit
}

\author{
E.A. Zakhar'ian
}

State Educational Institution of Higher Professional Education The Mechnikov North-West State Medical University, St. Petersburg

\section{ВВЕДЕНИЕ}

Актуальность данной проблемы:

- Сложность достижения консолидации костных фрагментов костей голени у детей с врожденными ложными суставами.

- Значительное укорочение и деформация костей голени, возникшие в результате прогрессирования заболевания или ранее проведенных оперативных вмешательств.

- Необходимость выполнения коррекции деформаций костей голени с целью улучшения опорной функции пораженной конечности и профилактики повторных переломов.

- Невозможность проведения остеотомий большеберцовой кости на вершине деформации (вершина деформации чаще является областью консолидации фрагментов кости зоны бывшего ложного сустава).

\section{МАТЕРИАЛЫ И МЕТОДЫ}

Всем пациентам выполнялось:

- Панорамная рентгенограмма нижних конечностей в двух стандартных проекциях.

- Определение референтных значений углов большеберцовой кости.

- Определение укорочения пораженной нижней конечности.

- Планирование коррекции деформации согласно общепринятой методике, составление скиаграмм самостоятельно или при помощи программного обеспечения предоперационного планирования (прим. «TraumaCad»).

- Выполнение оперативных вмешательств согласно проведенному планированию.

- Удлинение костей голени при помощи аппарата внешней фиксации.

- Выполнение коррекции деформации большеберцовой кости репозиционным узлом «ОРТО-СУВ».

- Оценка полученных результатов, сравнение с раннее проведенным планированием.

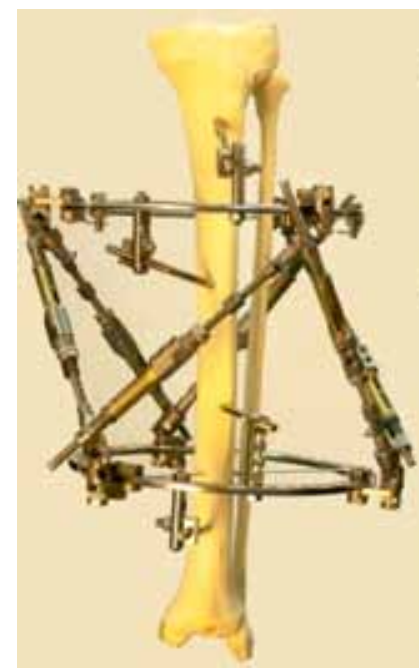

Reference lines and angles (RLA)
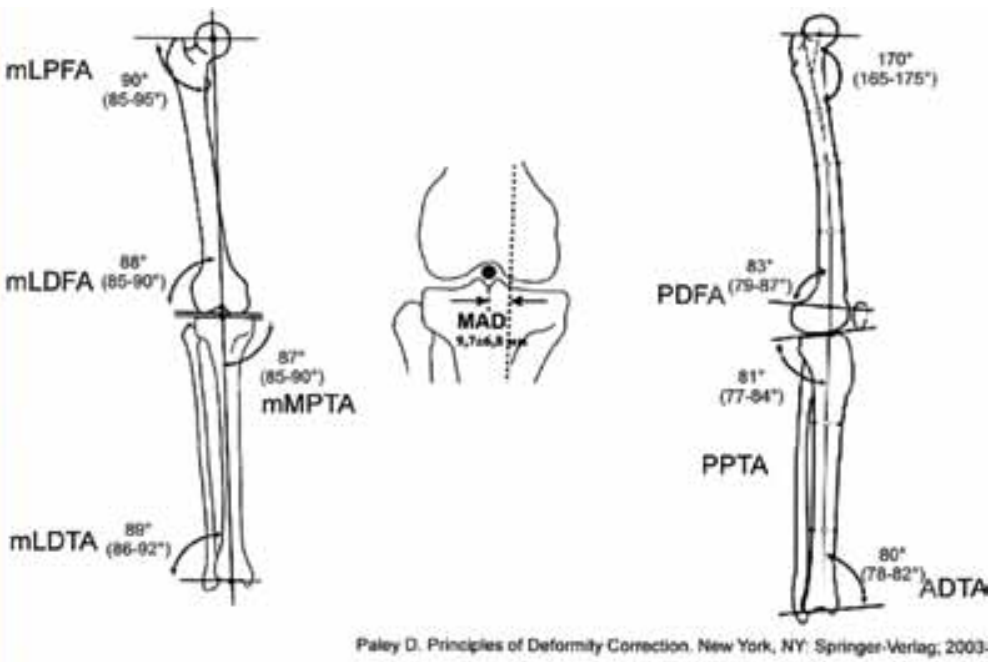
Журнал клинической и экспериментальной ортопедии им. Г.А. Илизарова № 3, 2015 г.

В исследование включено 12 пациентов, которым проводилось лечение по вышеописанной методике.

\begin{tabular}{|c|c|c|c|}
\hline \multicolumn{3}{|c|}{ Количество пациентов, всего 12 } \\
\hline \multicolumn{2}{|c|}{ Мальчики } & Кол-во & $\%$ \\
\hline Кол-во & $\%$ & 3 & 25 \\
\hline 9 & 75 & & \multicolumn{2}{c|}{ Девочки } \\
\hline
\end{tabular}

После проведенного планирования пациенты разделились на 2 группы:

Группа 1 - остеотомия костей голени на двух уровнях (проксимальная и дистальная трети).

Группа 2 - остеотомия костей голени в проксимальной трети.

\begin{tabular}{|c|c|c|c|}
\hline \multicolumn{3}{|c|}{ Количество пациентов, всего 12 } \\
\hline \multicolumn{2}{|c|}{ Остеотомия на 2-х уровнях } & Остеотомия в верхней трети \\
\hline Кол-во & $\%$ & 6 & 50 \\
\hline 6 & 50 & Кол-во \\
\hline
\end{tabular}

\section{ДискУССИЯ}

Среднее значение референтных углов и укорочения большеберцовой кости до коррекции деформации в группах

\begin{tabular}{|c|c|c|c|c|}
\hline \multicolumn{5}{|c|}{ Группа 1 } \\
\hline mMPTA & mLDTA & PРTA & ADTA & Укорочение \\
\hline $95 \pm 4$ & $86 \pm 25$ & $81 \pm 6$ & $99 \pm 19$ & $6,5 \pm 3,5$ \\
\hline \multicolumn{5}{|c|}{ Группа 2} \\
\hline mМРTA & mLDTA & РРTA & ADTA & Укорочение \\
\hline $89 \pm 7$ & $89 \pm 7$ & $82 \pm 6$ & $85 \pm 5$ & $6,6 \pm 4,2$ \\
\hline
\end{tabular}
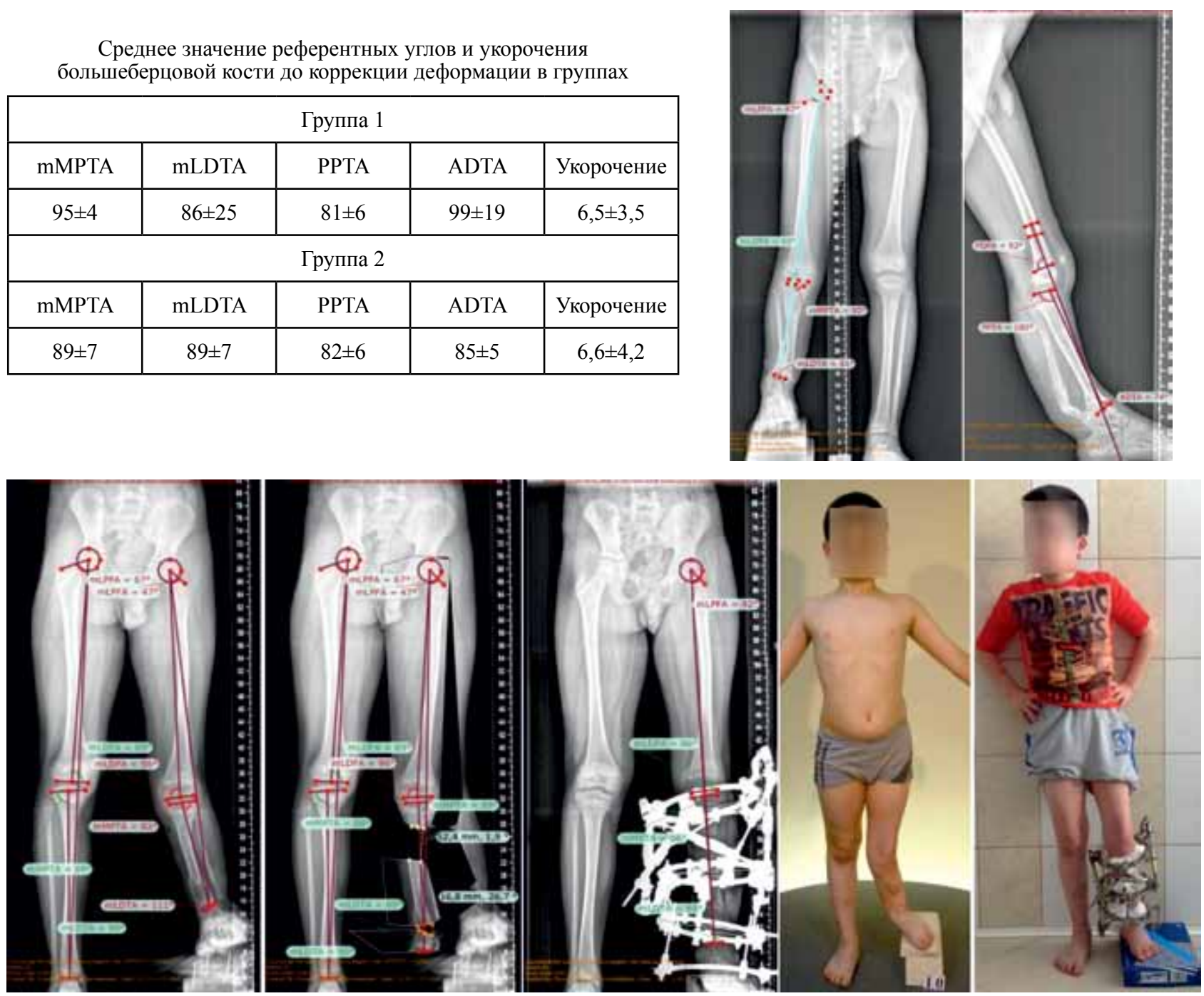

Результат планирования и коррекции деформации костей голени при выполнении остеотомий на 2-х уровнях у детей с ВЛСКГ

Среднее значение референтных углов и укорочения большеберцовой кости после коррекции деформации

\begin{tabular}{|c|c|c|c|c|}
\hline \multicolumn{5}{|c|}{ Группа 1 } \\
\hline mMPTA & mLDTA & РРТА & ADTA & Укорочение \\
\hline $87 \pm 2$ & $86 \pm 3$ & $78 \pm 4$ & $82 \pm 7$ & 5,5 см $(1$ пац. $)$ \\
\hline
\end{tabular}



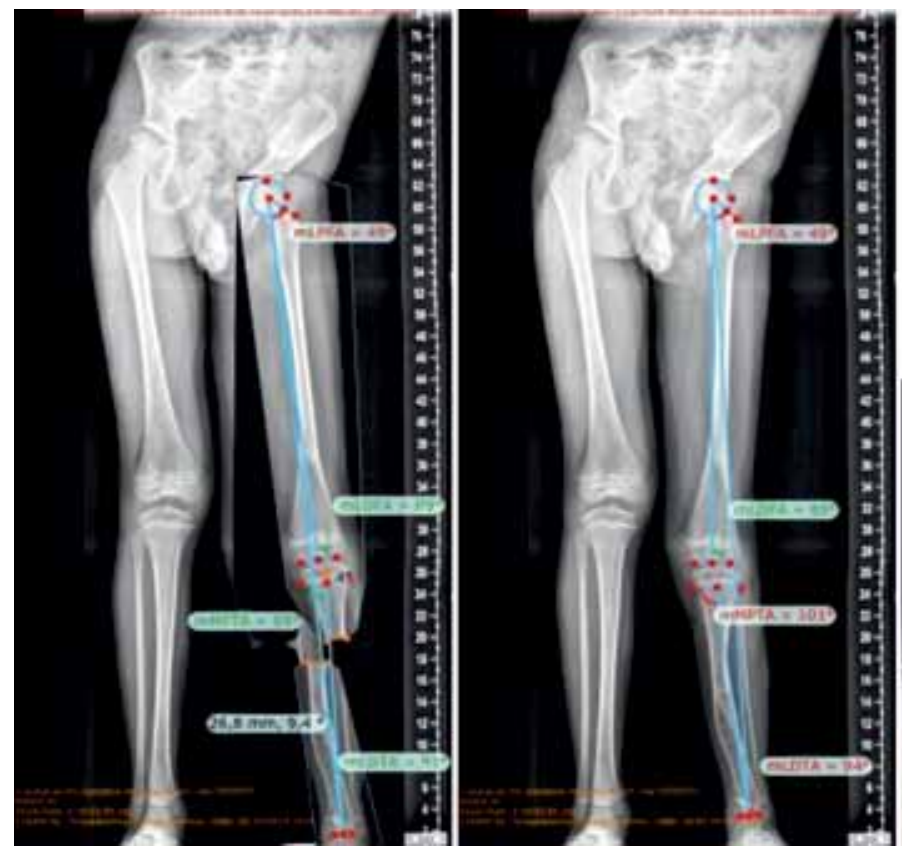

Результат планирования и коррекции деформации костей голени при выполнении остеотомий на одном уровне у детей с ВЛСКГ

Среднее значение референтных углов и укорочения большеберцовой кости после коррекции деформации в группе 2

\begin{tabular}{|c|c|c|c|c|}
\hline \multicolumn{5}{|c|}{ Группа 2 } \\
\hline mMPTA & mLDTA & РРTA & ADTA & Укорочение \\
\hline $88+2$ & $87+3$ & $81+3$ & $81+3$ & $4,8+1(3$ пац.) \\
\hline
\end{tabular}

\section{ЗАКЛЮЧЕНИЕ}

- При выполнении коррекции деформаций костей голени у пациентов с ВЛСКГ не рекомендуется выполнять остеотомии в области зоны бывшего ложного сустава из-за опасности рецидива.

- Проведение предоперационного планирования позволяет определить и визуализировать наиболее лучшие позиции остеотомий для достижения точной коррекции деформаций.

- Выполнение остеотомий на двух уровнях позволяет достичь точной коррекции деформаций без значительного смещения фрагментов по ширине, тем самым не нарушая равномерное распределение нагрузки на оперированной нижней конечности.

- В случаях, когда невозможно выполнить остеотомию костей голени в нижней трети для достижения коррекции деформации, можно выполнить остеотомию только в верхней трети большеберцовой кости.

- Для нивелирования значительного «коленвала» остеотомию только в верхней трети лучше выполнять у пациентов, которым требуется удлинение конечности от 3 см.

- Применение устройств с пассивной компьютерной навигацией (репозиционный узел «ОРТО-СУВ») позволяет сократить время и достичь точности коррекции деформаций.

- Всем пациентам с первых дней выполнения коррекции деформаций необходимо проводить курс восстановительного лечения с целью сохранения амплитуды движения в коленном суставе.

\section{ЛИТЕРАТУРА}

1. Поздеев А.П., Захарьян Е.А. Особенности течения врожденных ложных суставов костей голени у детей дистрофического и диспластического генеза // Ортопедия, травматология и восстановительная хирургия детского возраста. СПб., 2014. Т. 2, вып. 1. С. 78-84.

2. Определение референтных линий и углов длинных трубчатых костей : пособие для врачей / [сост.]: Л.Н. Соломин, Е.А. Щепкина, П.Н. Кулеш, К.Л. Корчагин, А.А. Лоздовский, П.В. Скоморошко. СПб.: РНИИТО им. Р.Р. Вредена, 2010. 46 с.

3. Khan T., Joseph B. Controversies in the management of congenital pseudarthrosis of the tibia and fibula // Bone Joint J. 2013. Vol. 95-B, No 8. P. 1027-1034.

4. Paley D., Tetsworth K. Mechanical axis deviation of the lower limbs. Preoperative planning of multiapical frontal plane angular and bowing deformities of the femur and tibia // Clin. Orthop. Relat. Res. 1992. No 280. P. 65-71.

5. Pannier S. Congenital pseudarthrosis of the tibia // Orthop. Traumatol. Surg. Res. 2011. Vol. 97, No 7. P. $750-761$.

\section{REFERENCES}

1. Pozdeev A.P., Zakhar'ian E.A. Osobennosti techeniia vrozhdennykh lozhnykh sustavov kostei goleni u detei distroficheskogo i displasticheskogo geneza [The details of the course of congenital leg bone pseudoarthroses in children with dystrophic and dysplastic genesis] // Ortopediia, Travmatologiia $\mathrm{i}$ Vosstanovitel'naia Khirurgiia detskogo vozrasta. SPb., 2014. T. 2, Vyp. 1. S. 78-84.

2. Opredelenie referentnykh linii i uglov dlinnykh trubchatykh kostei: posobie dlia vrachei [Determination of reference lines and angles of long tubular bones: a manual for physicians] / [sost.]: L.N. Solomin, E.A. Shchepkina, P.N. Kulesh, K.L. Korchagin, A.A. Lozdovskii, P.V. Skomoroshko. SPb.: RNIITO im. R.R. Vredena, 2010. $46 \mathrm{~s}$.

3. Khan T., Joseph B. Controversies in the management of congenital pseudarthrosis of the tibia and fibula // Bone Joint J. 2013. Vol. 95-B, No 8. P. 1027-1034.

4. Paley D., Tetsworth K. Mechanical axis deviation of the lower limbs. Preoperative planning of multiapical frontal plane angular and bowing deformities of the femur and tibia // Clin. Orthop. Relat. Res. 1992. No 280. P. 65-71.

5. Pannier S. Congenital pseudarthrosis of the tibia // Orthop. Traumatol. Surg. Res. 2011. Vol. 97, No 7. P. $750-761$. 